\section{Case Reports in Ophthalmology}

\title{
Bilateral Ocular Decompression Retinopathy after Ahmed Valve Implantation for Uveitic Glaucoma
}

\author{
Javier Flores-Preciado David Arturo Ancona-Lezama \\ Carlos Andrés Valdés-Lara Gian Franco Díez-Cattini Itziar Coloma- \\ González \\ Hospital Luis Sánchez Bulnes, Asociación para Evitar la Ceguera en México, I.A.P., Mexico \\ City, Mexico
}

\section{Keywords}

Ocular decompression retinopathy · Ahmed valve · Uveitic glaucoma

\begin{abstract}
Case Report: We report the case of a 29-year-old man who underwent Ahmed valve implantation in both eyes as treatment for uveitic glaucoma, subsequently presenting with bilateral ocular decompression retinopathy in the postoperative period. Discussion: Ocular decompression retinopathy is a rare complication of filtering surgery in patients with glaucoma; however, the course is benign in most cases, with spontaneous resolution of bleedings and improvement of visual acuity.

(C) 2016 The Author(s) Published by S. Karger AG, Basel
\end{abstract}

\section{Introduction}

Ocular decompression retinopathy (ODR) is a rare complication of filtering surgery in glaucoma patients, described by Fechtner et al. in 1992 [1]. It is defined as acute multifocal hemorrhagic retinopathy that occurs following an acute decrease of intraocular pressure (IOP) and that cannot be explained by any other pathological process [2]. It is described as appearance of diffuse retinal hemorrhages often with white spots in the center, sometimes 
Flores-Preciado et al.: Bilateral Ocular Decompression Retinopathy after Ahmed Valve Implantation for Uveitic Glaucoma

associated with a decrease in visual acuity. Less commonly it presents with macular edema or serous macular detachment [3]. It has been described in trabeculectomy, Ahmed valve implantation, peripheral iridotomy, anterior chamber paracentesis, deep sclerotomy, ExPRESS shunt implantation, and IOP-lowering medication use [4]. Our presented case concerns a rare entity in ophthalmology, particularly with respect to the bilateral presentation.

\section{Case Report}

We present a 29-year-old male who was admitted to our hospital with a previous diagnosis of increased IOP for 8 months in treatment with a combined drop of timololdorzolamide-brimonidine every $12 \mathrm{~h}$ and bimatoprost every $24 \mathrm{~h}$ in both eyes. The patient was referred having had LASIK surgery a year before admission.

His ophthalmologic exam revealed a best corrected visual acuity (BCVA) of 0.20 LogMAR in both eyes. His IOP was $34 \mathrm{~mm} \mathrm{Hg}$ in the right eye (OD) and $38 \mathrm{~mm} \mathrm{Hg}$ in the left eye (OS), examination of the anterior segment was only relevant for a clear well-positioned LASIK flap and a gonioscopically open anterior chamber angle, and fundus examination revealed glaucomatous optic disc cupping of $80 \%$ in both eyes and peripheral vascular sheathing. No signs of media opacity, retinal hemorrhage, macular or peripheral detachments, or other abnormalities were observed in either eye. Automated visual fields were obtained to confirm glaucomatous visual field defect. Suspecting peripheral retinal vasculopathy, fluorescein angiography was performed revealing dye leakage with parietal staining of peripheral vessels. Blood work was ordered to rule out rheumatologic, infectious, and thromboembolic etiologies for retinal vasculitis. All tests were negative.

In the following week, IOP was poorly controlled in spite of maximum medical treatment and IOP values remained consistently over $30 \mathrm{~mm} \mathrm{Hg}$. An Ahmed valve implantation was scheduled and performed sequentially in both eyes. On the first postoperative day, BCVA was $1.00 \mathrm{OD}$ and $0.50 \mathrm{OS}$, and IOP was 0 and $3 \mathrm{~mm} \mathrm{Hg}$, respectively. Slit-lamp examination revealed a functional filtering bleb, a formed anterior chamber and a free tube opening. Pupillary response was somewhat delayed and a slight afferent pupillary defect was present. Fundus examination showed blurred, hyperemic optic disc with peripapillary hemorrhages and scattered white-centered retinal hemorrhages in the periphery and posterior pole in both eyes accompanied with macular folds in the OS (Fig. 1). Early postoperative treatment with prednisolone acetate $1 \%$ q.i.d. and atropine $1 \%$ t.i.d. was initiated. At the postoperative week, a new fluorescein angiography revealed blockage hypofluorescence in the areas of intraretinal hemorrhages and disc hyperfluorescence but no delay in venous filling (Fig. 2), leading to the diagnosis of decompression retinopathy in both eyes (OU) and hypotonic maculopathy of the OS. One week postoperatively, his IOP was $10 \mathrm{~mm} \mathrm{Hg}$ in OU, BCVA was $0.70 \mathrm{OD}$ and $0.40 \mathrm{OS}$, and the retinal hemorrhages began to resolve. One month after surgery, the retinal hemorrhages showed gradual reduction in size. (Fig. 3). At the third month of follow-up, BCVA improved to $0.40 \mathrm{OD}$ and $0.30 \mathrm{OS}$, and IOP was $16 \mathrm{~mm} \mathrm{Hg}$ in OU. Fundal hemorrhages had faded and hypotonic maculopathy had resolved.

\section{Discussion}

ODR is a well-known complication that has been previously described in penetrating and nonpenetrating ocular surgeries such as trabeculectomy with or without antimetabo- 
lites, Ahmed valve implantation, anterior chamber paracentesis, vitrectomy, phacoemulsification, orbital decompression surgery, and less invasive procedures such as peripheral iridotomies and IOP-lowering medication [2-9]. The mean drop of IOP reported is $33.2 \pm 15.8$ $\mathrm{mm} \mathrm{Hg}$ (range, 4-57 mm Hg) [3].

The pathophysiology is still unknown, but it is believed to be associated with a loss of the autoregulatory capacity of retinal vessels. When the IOP drops, the vessels are unable to respond to abrupt pressure changes causing spontaneous bleeding. It is also thought as a variant of central retinal vein occlusion triggered when the sudden IOP drop causes a shift in the cribriform plate that effectively blocks axonal and vascular flow in the optic nerve head causing postcapillary venous stasis, hemorrhages, and retinal edema $[1-3,10,11]$.

Only $20 \%$ of patients show decreased visual acuity, central scotoma, or myodesopsias. The clinical findings are sub-, intra-, and preretinal (subhyaloid and vitreal) hemorrhages, mainly in the posterior pole. Twenty percent can have a white spot in the center of the hemorrhage. The optic nerve can be hyperemic, with edema and/or hemorrhage, and with vascular tortuosity [2-4].

ODR has a benign course with resolution of the complete clinical picture within 2-72 weeks with typical improvement of visual acuity in most of the cases as the hemorrhages fade $[2,6]$. Visual outcome is good most of the times, with visual acuity returning to baseline vision in $85 \%$ of the cases. Some authors have reported a mean drop in visual acuity from $20 / 50$ to $20 / 100$, but still no intervention is required for most of the patients [3]. Our patient's final BCVA was 0.40 OD and 0.30 OS. Despite not returning to the initial visual acuity, it could be considered a positive outcome.

The main differential diagnosis for ODR is central retinal vein occlusion. Venous occlusion was ruled out because there was no angiographic evidence of venous dilatation, delayed venous filling, or occlusive phenomena as is expected in acute central retinal vein occlusion. The differential diagnosis of ODR and other vascular disorders, including Valsalva retinopathy, Terson syndrome, and diabetic retinopathy, should be considered.

Preoperative aggressive IOP-lowering treatment can prevent the development of ODR and other decompressive complications such as choroidal hemorrhage. It is advised to use intravenous agents such as mannitol or oral glycerin in addition to topical IOP lowering in such cases to reduce morbidity and achieve stable IOP measurement postoperatively [12].

The fact that our patient had bilateral ODR suggests impaired retinal vasculature autoregulation capacity, probably showing individual susceptibility. To the best of our knowledge, this is the first report of bilateral decompression retinopathy after Ahmed valve surgery.

\section{Statement of Ethics}

The authors have no ethical conflicts to disclose.

\section{Disclosure Statement}

None of the authors have any conflicts of interest in regard to the material in this case report. 
Flores-Preciado et al.: Bilateral Ocular Decompression Retinopathy after Ahmed Valve Implantation for Uveitic Glaucoma

\section{References}

-1 Fechtner R, Minckler D, Weinreb R, Frangei G, Jampol L: Complications of glaucoma surgery. Ocular decompression retinopathy. Arch Ophthalmol 1992;110:965-968.

-2 Mukkamala SK, Patel A, Dorairaj S, McGlynn R, Sidoti P, Weinreb R, et al: Ocular decompression retinopathy: a review. Surv Ophthalmol 2013;58:505-512.

-3 Figueiredo ARM, Sampaio IC, dos Santos Menéres MJF, Spaeth GL: Consecutive bilateral decompression retinopathy after mitomycin C trabeculectomy: a case report. J Med Case Rep 2016;10:32.

4 Li GY, Alantaree S, Wang JM, Zhang H: Ocular decompression retinopathy following canaloplasty for primary open angle glaucoma: a case report. Medicine 2016;95:e2907.

-5 Danias J, Rosenbaum J, Podos SM: Diffuse retinal hemorrhages (ocular decompression syndrome) after trabeculectomy with mitomycin C for neovascular glaucoma. Acta Ophthalmol Scand 2000;78:468-469.

-6 Arevalo JF, Mendoza AJ, Millan FA, Fuenmayor D: Simultaneous bilateral ocular decompression retinopathy after trabeculectomy with mitomycin C for uveitic glaucoma. Graefes Arch Clin Exp Ophthalmol 2008;246:471-473.

-7 Bansal A, Ramanathan U: Ocular decompression retinopathy after trabeculectomy with mitomycin-C for angle recession glaucoma. Indian J Ophthalmol 2009;57:153-154.

-8 Arévalo JF, Mendoza AJ, Fernández CF, Yépez JB, Krivoy D, Millán FA: Decompression retinopathy after intraocular surgery. Arch Soc Esp Oftalmol 2007;82:629-634.

-9 Samra KA, Sieminski SF, Sarup V: Decompression retinopathy after ExPRESS shunt implantation for steroid-induced ocular hypertension: a case report. Case Rep Ophthalmol Med 2011;2011:303287.

10 Rao SK, Greenberg PB, Macintyre RB, Ducharme JF: Ocular decompression retinopathy after anterior chamber paracentesis for uveitic glaucoma. Retina 2009;29:280-281.

11 Wakita M, Kawaji T, Ando E, Koga T, Inatani M, Tanihara H, Ando Y: Ocular decompression retinopathy following trabeculectomy with mitomycin $\mathrm{C}$ associated with familial amyloidotic polyneuropathy. $\mathrm{Br} \mathrm{J}$ Ophthalmol 2006;90:515-516.

-12 Saricaoglu MS, Kalayci D, Guven D, Karakurt A, Hasiripi H: Decompression retinopathy and possible risk factors. Acta Ophthalmol 2009;87:94-95. 


\section{Case Reports in Ophthalmology}

\section{Case Rep Ophthalmol 2016;7:227-232}

DOI: $10.1159 / 000452268$

C 2016 The Author(s). Published by S. Karger AG, Basel www.karger.com/cop

Flores-Preciado et al.: Bilateral Ocular Decompression Retinopathy after Ahmed Valve Implantation for Uveitic Glaucoma

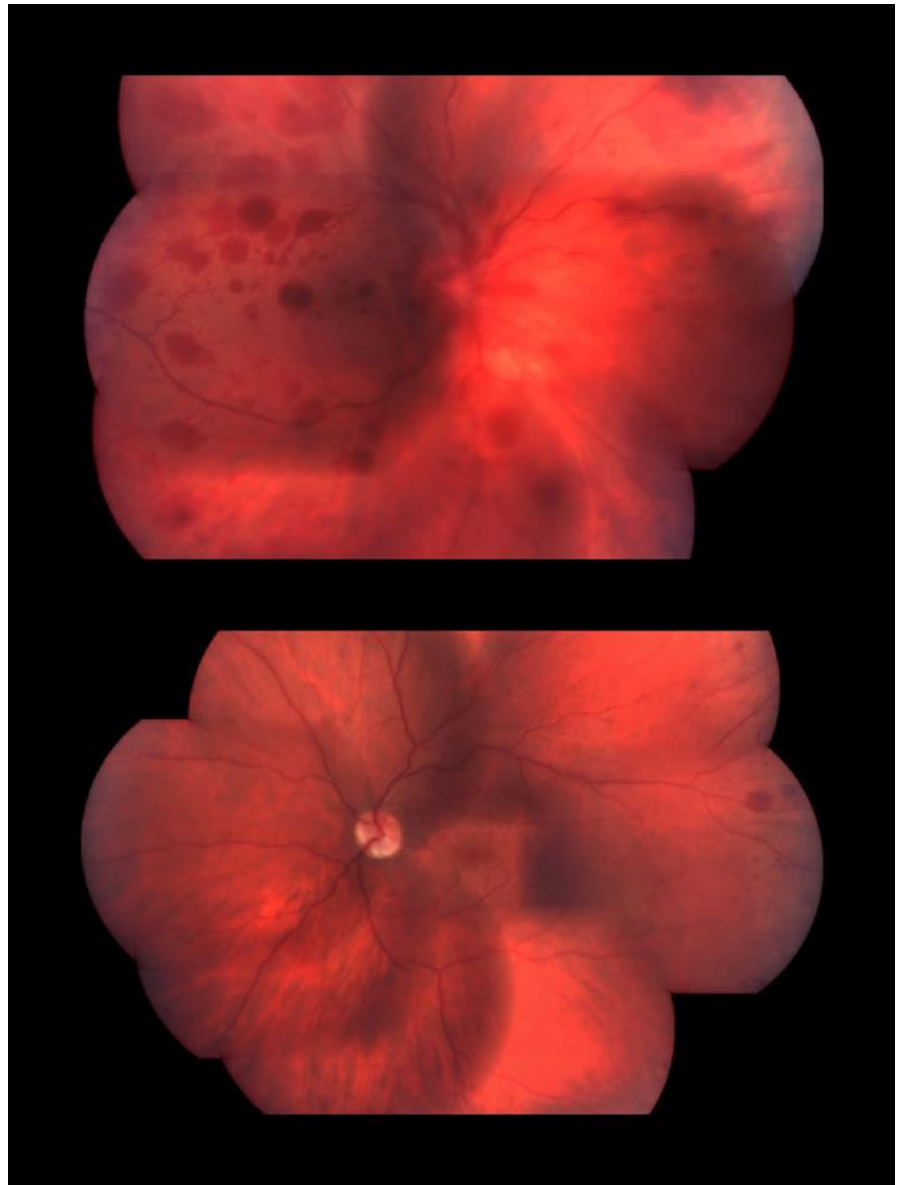

Fig. 1. Fundus examination showing blurred, hyperemic optic disc with peripapillary hemorrhages and scattered white-centered retinal hemorrhages in the periphery and posterior pole in both eyes accompanied with macular folds in the OS. 


\section{Case Reports in Ophthalmology} www.karger.com/cop

Flores-Preciado et al.: Bilateral Ocular Decompression Retinopathy after Ahmed Valve Implantation for Uveitic Glaucoma

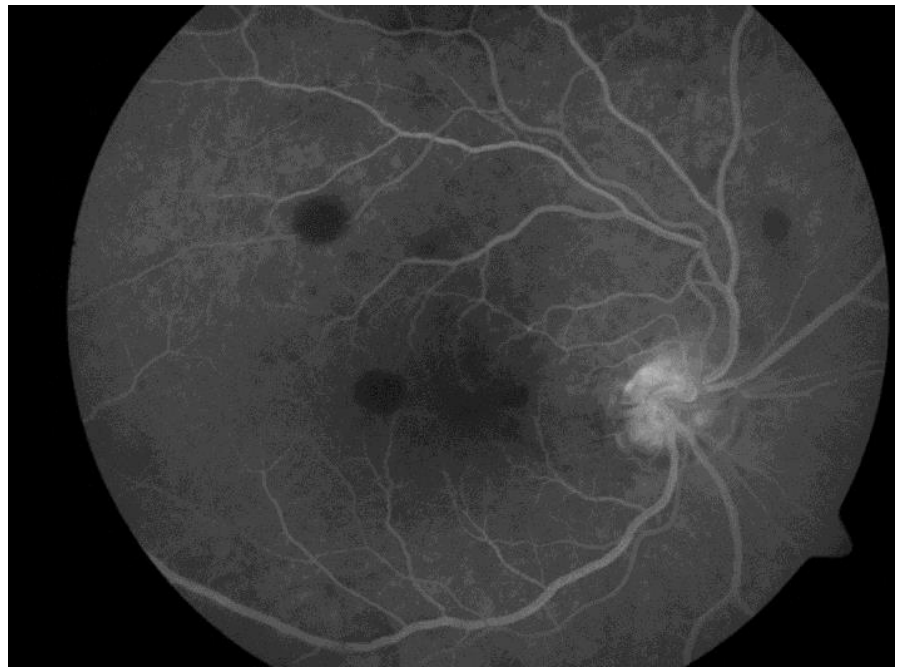

Fig. 2. Fluorescein angiography at the postoperative week revealing blockage hypofluorescence in the areas of intraretinal hemorrhages and disc hyperfluorescence but no delay in venous filling

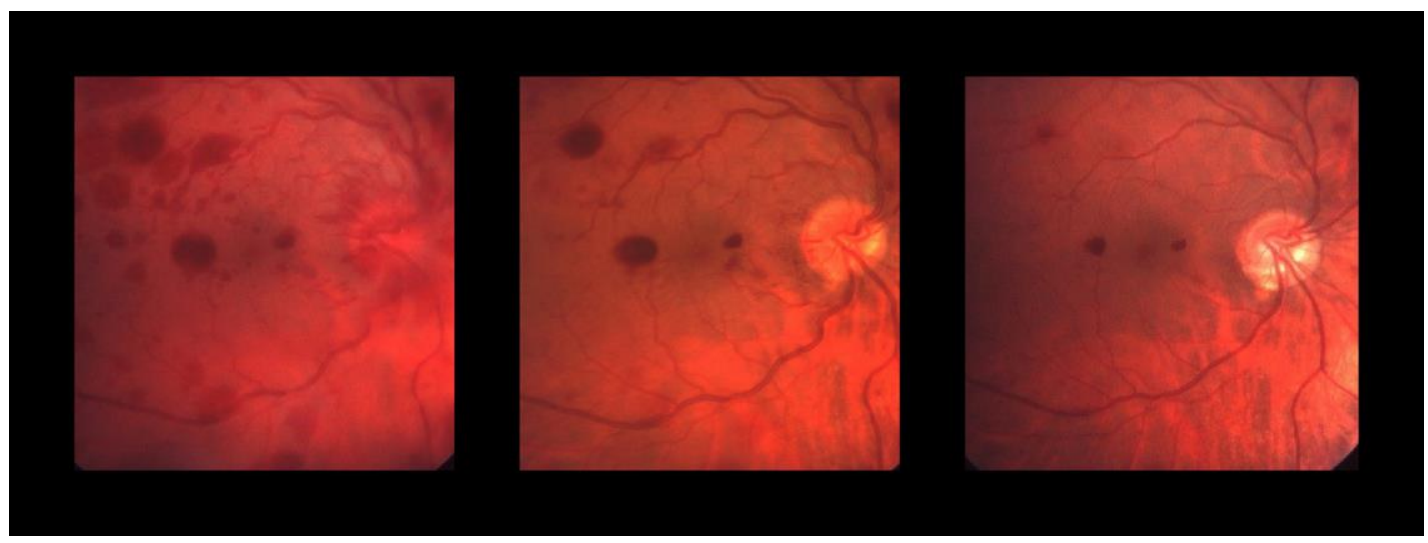

Fig. 3. Retinal hemorrhages showing gradual reduction in size 1 month after surgery. 